\title{
PREVALENCE AND ANATOMICAL PATTERN OF THE MEDIAN ARTERY AMONG ADULT BLACK KENYANS
}

\author{
Isaac Cheruiyot, Brian Bundi, Jeremiah Munguti, Beda Olabu, Brian Ngure, Julius Ogeng'o
}

Correspondence to Dr. Julius Ogeng'o, Department of Human Anatomy, University of Nairobi, Corresponding Author: Julius Ogeng'o. E- Mail: jogengo@uonbi.ac.ke

\begin{abstract}
Knowledge of the anatomy of median arteries is important in the diagnosis and management of carpal tunnel and pronator teres syndromes, reconstructive surgery in the forearm, minimizing inadvertent vascular injury as well as in limiting operative complications due to unexpected bleeding. The anatomical pattern displays ethnic differences but there are few studies on black Africans. This study therefore sought to describe the anatomy of median arteries in an adult black Kenyan population. A total of sixty two (62) upper limbs from thirty one (31) formalin-fixed cadavers were studied at the Department of Human Anatomy, University of Nairobi, Kenya. The prevalence, origin, types, relationship with median nerves and termination were determined. Median arteries were observed in 37 $(59.7 \%)$ cases. Of these, the palmar type comprised $12(32.4 \%)$ and antebrachial type $25(67.6 \%)$ cases. It occurred bilaterally in $14(45.2 \%)$ cases. The most common origin was the common interosseous artery $(21 ; 56.8 \%)$ followed by anterior interosseous $(13 ; 35.1 \%)$ and ulnar $3(8.1 \%)$ arteries. The artery pierced the median nerve in 7 (18.9\%) cases. The palmar type terminated by uniting with the ulnar artery to form a median-ulnar type of superficial palmar arterial arch in 8 $(21.6 \%)$ cases and directly gave rise to the first, second and third common digital arteries in 4 (10.8\%). In conclusion, the median artery occurs in nearly $60 \%$ of the population, much higher than in prevailing literature reports. Prevalence of the palmar type of median arteries and that of median arteries piercing median nerves are also higher than in other populations. Accordingly, presence of median artery and consequently other vascular and median nerve variations should be considered in the differential diagnosis of forearm entrapment neuropathies and due caution taken during forearm surgical procedures. We recommend preoperative ultrasound evaluation of the forearm and hand vascular system.
\end{abstract}

Keywords: Median artery, origin, prevalence, median nerve, Kenyan

\section{INTRODUCTION}

Median artery is a transitory vessel that represents the embryonic arterial axis of the forearm. It usually regresses into a thin vessel that supplies the median nerve, to be replaced by the ulnar and the radial arteries during the eight week of gestation (Eid et al., 2011; Agarwal et al., 2013). It may, however, persist in adults in one of two patterns namely, palmer or antebrachial. The palmar type represents the embryonic pattern, and is therefore sometimes referred to as the persistent median artery (PMA). The PMAs are usually long, prominent vessels which extend to the palmar aspect of the hand. The antebrachial type, on the other hand, represent partial regression of the axial artery, are usually short, narrow and limited to the forearm (Rodriguez-Niedenfuhr et al., 1999; Aragao, 2017). Median arteries are clinically

Submitted $7^{\text {th }}$ June 2017, revised on $7^{\text {th }}$ September 2017. Published online $12^{\text {th }}$ Nov 2017 . To cite: Cheruiyot I, Bundi B, Munguti J, Olabu B, Ngure B, Ogeng'o J. Prevalence and anatomical pattern of the median artery among adult black Kenyans. Anatomy Journal of Africa. 2017. Vol 6 (3): $1015-1023$. 
important for several reasons: first, because of their superficial location, they are vulnerable to injury; secondly, they may cause compression neuropathies like carpal tunnel syndrome; thirdly, they are associated with other variations of upper limb arteries and median nerve (Gassner et al., 2002; Natsis et al., 2009; Salter et al., 2011; Raviprassan and Dakshayani, 2014; Agarwal et al., 2014); fourthly, their injury may cause ischemia of the hand and forearm when they constitute the major source of blood supply (Tsuruo et al., 2006; Agarwal et al., 2014; Patnaik and Paul, 2016); fifthly, they may be used as a graft artery (Arifoglu et al., 2008; Agarwal et al., 2013; Kandori et al., 2015); and finally during surgical procedures in the forearm or the wrist and median nerve block, their inadvertent injury may cause unexpected troublesome bleeding (Stimpson and Gupta, 2012). Accordingly, accurate knowledge of their anatomical pattern is critical in understanding upper limb vascularization and mitigating the potential surgical risks.

The anatomical pattern of the median artery shows ethnic and geographical variations (Shrivastava and Pande, 1990; George and Henneberg, 1996; Kopuz et al., 1997; Kandori et al., 2015). Consequently, population specific data are critical in guiding surgery. Pertinently, reconstructive flap surgery of the fore arm and hand are gaining prominence in Kenya (Nangole et al., 2015). There are, however, only a few studies from Africa (Henneberg and George, 1992; George and Henneberg, 1996) and none from the East African region. Consequently, little is known about this artery in the black African populations. The aim of this study is therefore to determine the anatomical pattern of the median arteries among black Kenyans.

\section{MATERIALS AND METHODS}

This was a descriptive cadaveric study conducted at the Department of Human Anatomy University of Nairobi, Kenya. A total of sixty two (62) upper limbs from thirty-one (31) formalin fixed cadavers of adult black Kenyans aged $25-72$ years ( 24 males, 7 females) were studied. The limbs were categorized into those of males and those of females, then right and left. Two longitudinal skin incisions were made. A lateral one running from the coracoid process to the base of the thumb and a medial one from the axilla to the base of the digiti minimi. The anterior skin flap and fascia were removed and the cubital fossa, the flexor compartment of the forearm and the palmar aspect of the hand exposed. Flexor digitorum superficialis muscle was detached from its origin, and reflected distally to expose the arteries of the forearm. Careful dissection of the brachial artery and its terminal branches was done.
Median artery was identified as that artery other than the ulnar, radial and interosseus arteries found in the middle of the flexor compartment. The artery was defined as antebrachial if it ended at or proximal to the wrist and palmer if it transversed the carpal tunnel to enter the palm. For the palmar types, the carpal tunnel was opened carefully and the artery followed to its point of termination on the palmar aspect of the hand. The arteries with which it anastomosed were examined.

Prevalence, origin, type, course in relation to median nerve and termination were determined. The data obtained were entered into SPSS software (Version 21.0, Chicago, Illinois) for analysis. The Paired Student's t-test was used to compare the above variables between the right and left sides. A $p$-value of $<0.05$ was considered significant at a $95 \%$ confidence interval. 


\section{RESULTS}

Arteries of the forearm and hand were visible in all sixty two upper limbs. Observations were made for all the variables in question namely the prevalence, origin, type, course in relation to the median nerve and pattern of termination.

\section{Prevalence}

Median arteries were observed in 37 (59.7\%) of the 62 limbs. In $14(37.8 \%)$ they were bilateral (Table 1). Twenty were on the right, while 17 were on the left. Out of the 37 median arteries, 25 (40.32\%) were antebrachial while $12(19.4 \%)$ were palmar. In the antebrachial variety, the arteries were slender, tapered off and terminated in the distal third of the forearm
[Fig 1A].The palmer definite reasonable arteries which ran the full extent of the forearm, traversed the carpal tunnel and entered the hand. There were no cases where the artery was anterior to the flexor retinaculum (Fig 1B).

\section{Origin}

The median arteries originated from the common interosseous artery in 21 (56.8\%) cases [Fig 2A], anterior interosseous artery in $13(35.1 \%)$ cases [Fig 2B] and ulnar artery in 3 $(8.1 \%)$ cases [Fig $2 \mathrm{C}]$.

Table 1: Side differences in the pattern of median arteries among adult black Kenyans

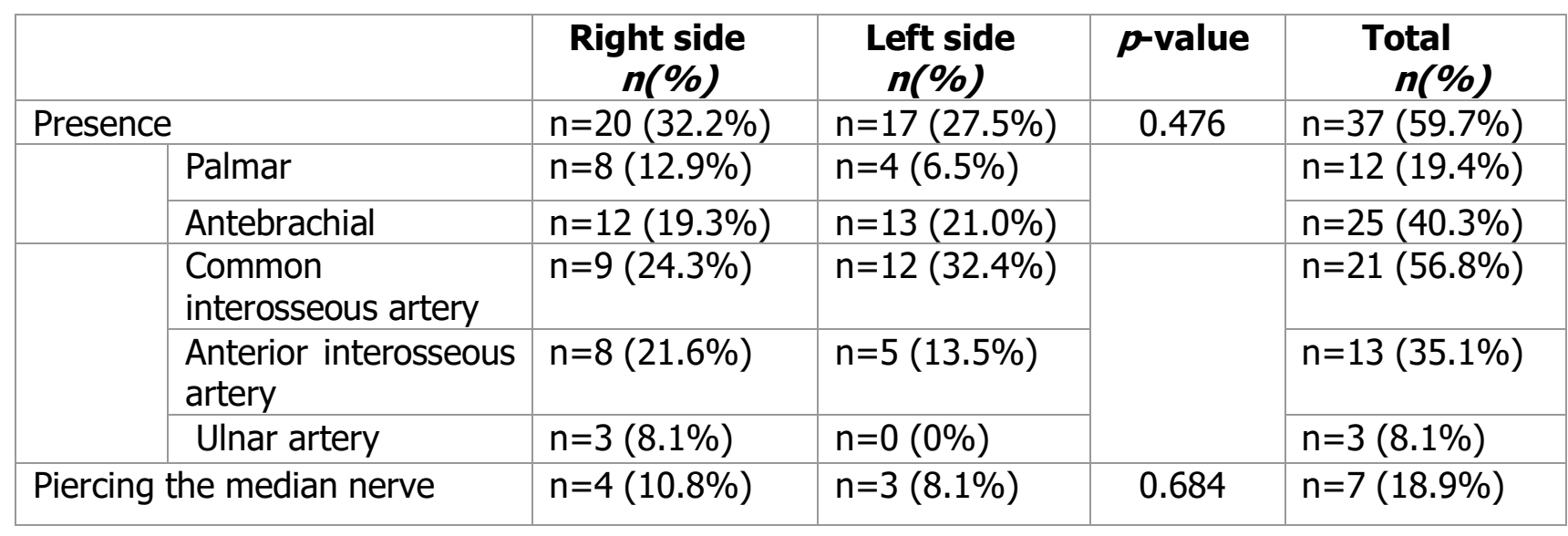
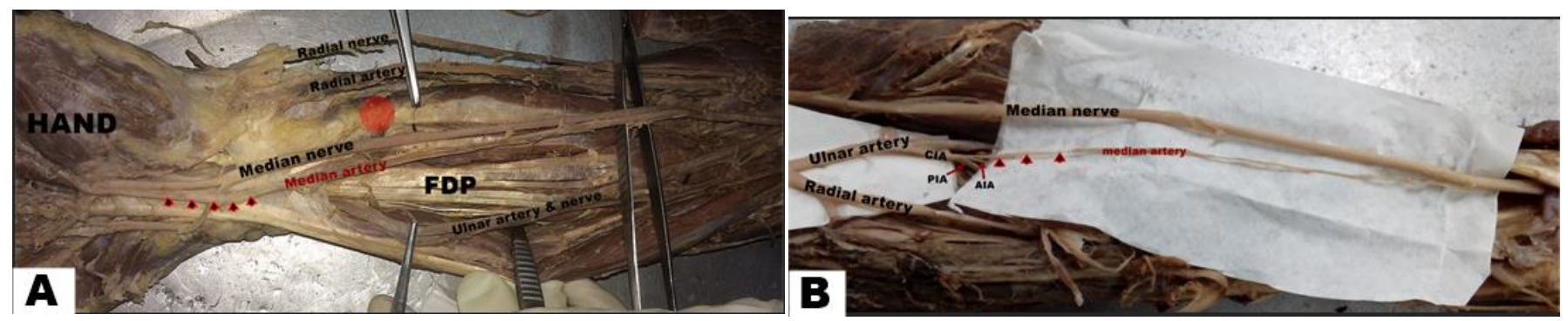

Figure 1: Types of Median artery. A: Palmar type of median artery (red arrows). Note the median artery extending to the palmar aspect of the hand, accompanied by the median nerve. FDP=Flexor digitorum profundus. B: Antebrachial type of the median artery. Note that it is short, thin and limited only to the forearm. CIA=common interosseous artery, AIA= Anterior interosseous artery; PIA = Posterior Interosseus Artery. 

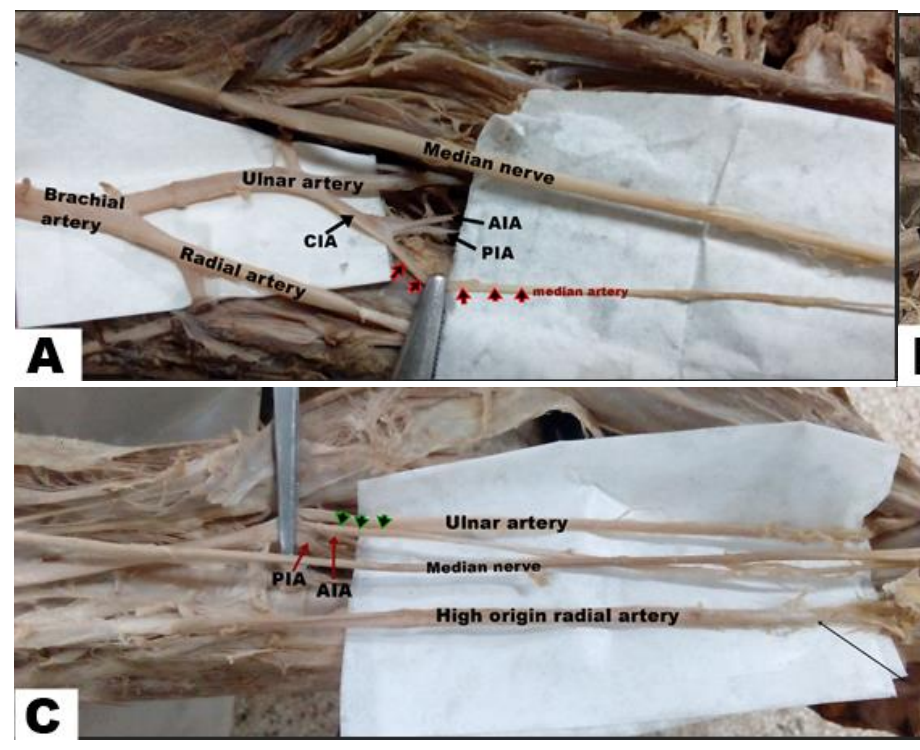

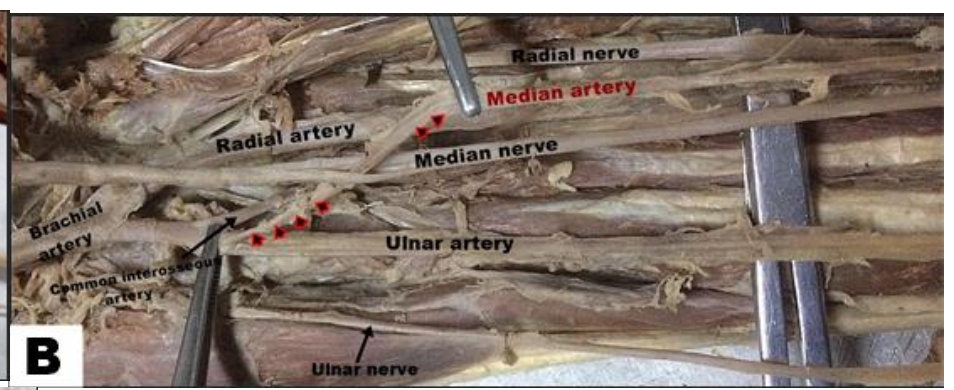

Fig 2: Origins of Median Artery. A: Median artery (red arrows) originating from the common interosseous artery $(\mathrm{CIA}) . \mathrm{AIA}=$ Anterior interosseous artery; PIA $=$ Posterior Interosseus Artery. B: Median artery (red arrows) originating from the ulnar artery. Note that it also pierced the median nerve in the proximal forearm. C: Median artery (green arrows) originating from the anterior interosseous artery. Note that the radial artery arises hiqh up in the mid-arm.

\section{Course in relation to the median nerve}

The median artery ran lateral to the median nerve in 12 cases, medial to it in 18 cases and pierced the median nerve in $7(18.9 \%)$ cases. In the latter cases, the arteries originated from the ulnar artery. The piercing occurred in the proximal one third of the forearm (Fig 3A, B).

\section{Pattern of termination}

The palmar type united with a superficial branch from the ulnar artery to form a median- ulnar type of complete superficial palmar arterial arch (SPA) [Fig 4A] in 8 (21.6\%) cases. The remaining $4(10.8 \%)$ terminated by giving rise to the first, second and third common digital arteries [Fig 4A,B]. No significant side differences were noted in the presence, type or origin of PMA.
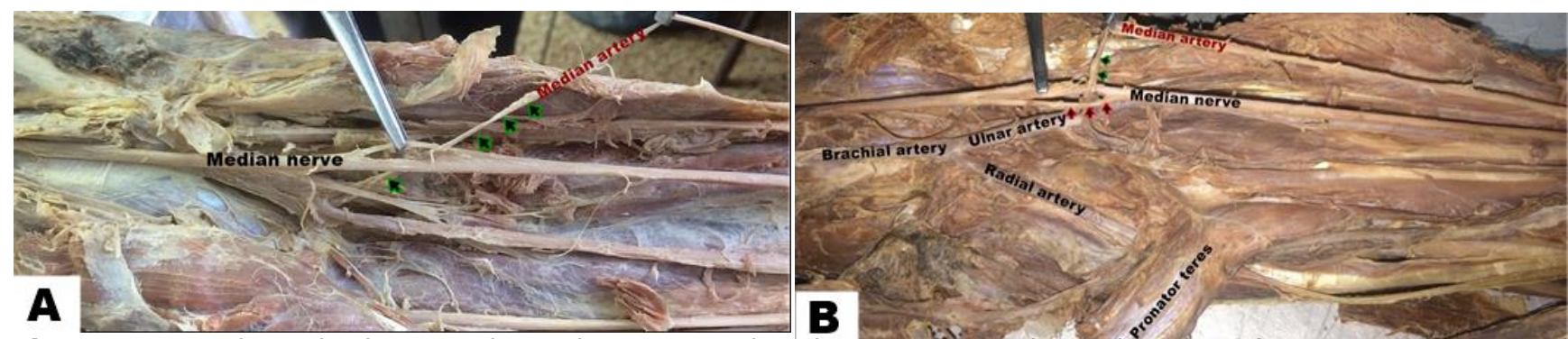

Figure 3A, B: Relationship between the median artery and median nerve. Note the median artery (green arrows) piercing the median nerve in the proximal forearm.
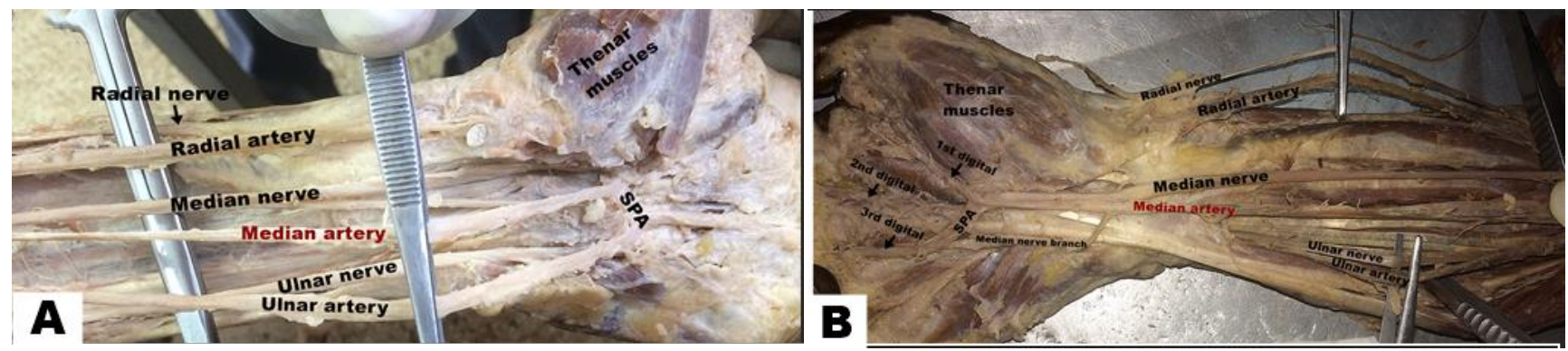

Figure 4: Pattern of termination of the palmar type of median artery. A: PMA uniting with the ulnar artery to form a median-ulnar type of a superficial palmar arterial arch (SPA). B: PMA giving rise to the $1^{\text {st }}, 2^{\text {nd }}$ and $3^{\text {rd }}$ common digital arteries. Note the anastomosis between third digital artery and the ulnar artery. 


\section{DISCUSSION}

The median artery may constitute an important source of blood and collateral circulation for the forearm and hand (Tsuruo et al., 2006; Agarwal et al., 2014; Patnaik and Paul, 2016). It is important to understand the prevalence, origin, course, relationship with median nerve and pattern of termination in order to avoid inadvertent injury (Nayak et al., 2010; Patnaik and Paul, 2016).

\section{Prevalence}

The prevalence of median arteries varies between 1.5 - 60\% (Natsis et al., 2009; Aung and Than, 2009; Agarwal et al., 2014; Henry et al., 2015). Observations of the current study reveal a prevalence of $57.9 \%$, which is comparable only to $60 \%$ among Malaysians (Aung and Than, 2009), but much higher than in other previous reports [Table 2].

\section{Type}

In the present study, the antebrachial and palmer types were observed in $67.6 \%$ and $32.4 \%$ of all cases respectively. The more frequent occurrence of the antebrachial type is consistent, with literature reports although lower than the $70-100 \%$ in contemporary literature (Natsis et al., 2009; Rodriguez Niederfur, 2009; Potu et al., 2011). A remarkable finding of the current study, however, is the $32.4 \%$ prevalence of PMA, comparable to $27.1 \%$ among black South Africans but otherwise higher than $4-23 \%$ in prevailing literature (Shrivastava and Pande, 1990; Henneberg and George, 1992; Aung and Than, 2009; Potu et al., 2011; Bilodi et al., 2014) [Table 2].

These wide variations may be related to differences in definition, denominators or method, but it is also probably related to ethnic and geographical variations. Indeed it has been suggested that the median arteries are more common in black populations (George and Henneberg, 1996). This suggests that surgeons operating in the forearm of this population should beware of this artery to avoid its inadvertent injury.

Table 2: Prevalence of median artery in various populations

\begin{tabular}{|l|l|l|l|}
\hline Reference & N & Population & $\begin{array}{l}\text { Percent } \\
\text { Prevalence }\end{array}$ \\
\hline Agarwal et al., 2014 & 52 & Indian & 11.53 \\
\hline Aung and Than, 2009 & 120 & Malaysian & 60 \\
\hline Chen et al., 2016 & 160 & Chinese & 7.5 \\
\hline Claassen et al., 2008 & 54 & German & 7.4 \\
\hline Eid et al., 2011 & 50 & Japanese & 4 \\
\hline Gassner et al., 2002 & 100 & Austrian & 26 \\
\hline Henneberg and George, 1999 & 96 & South Africans & 27.1 \\
\hline Milligan, 2013 & 223 & American & 19.2 \\
\hline Potu et al., 2011 & 50 & Indian & 8 \\
\hline Current study & 62 & Kenyan & 57.9 \\
\hline
\end{tabular}


Table 3: Prevalence of persistent median arteries among different populations

\begin{tabular}{|l|l|l|l|}
\hline Author & Population & N & Percent Prevalence \\
\hline Aung and Than, 2009 & Malaysian & 120 & 8.3 \\
\hline Claasen et al., 2008 & German & 54 & 7.4 \\
\hline Henneberg and George, 1992 & South African & 96 & 27.1 \\
\hline Natsis et al., 2009 & Greeks & 72 & 2.78 \\
\hline Patnaik and Paul, 2016 & Indians & 45 & 15.5 \\
\hline Rodriguez-Niedenfuhr et al.,1999 & Spaniards & 120 & 20 \\
\hline Present study & Kenyan & 32 & 32.4 \\
\hline
\end{tabular}

This suggests an ethnic difference, in which black Africans have a higher prevalence of PMA. This difference may be attributed to genetic factors, such as variations in the single nucleotide polymorphisms (SNPs) within the gene loci regulating the pattern of upper limb vascularization (Patnaik and Paul, 2016). This calls for more comparative studies among different ethnic communities.

\section{Origin}

Origin of MA is important during harvesting of forearm vascular flaps. For instance, the MA may be injured when harvesting ulnar (Lovie et al., 1984) or radial artery (Acarturk et al., 2008) flaps, resulting in ischemia of the hand, especially in cases where the MA constitutes its significant source of blood supply. The median artery is most commonly a branch of the ulnar (Aung and Thang, 2009; Natsis et al., 2009) followed by common interosseus, anterior interosseus, brachial and radial arteries (Varley et al., 2008; Arifoglu et al., 2008; Natsis et al., 2009; Aung and Than, 2009). In the present study, the MA originated from ulnar artery in only $8.1 \%$ of cases, instead predominantly arising from the common interosseous artery (CIA). This is concordant with the findings by Hennberg and George (1992), Nayak et al., (2009) and Aragão et al., (2017). It supports the ascertions that the MA may arise from any artery of the forearm and arm (Rodriguez Niederfuhr et al. 1999). The embryological basis for the variability is probably the pattern of development of the arterial supply of the forearm. The arteries develop from a capillary plexus that undergoes differentiation in a distalproximal fashion (Rodriguez-Niedenfuhr et al.,1999). Due care should therefore be taken during surgical and radiological procedures on the forearm and hand. In view of wide variability, preoperative Doppler Ultrasound evaluation is recommended.

\section{Relationship with the median nerve}

The $18.9 \%$ incidence of MA piercing the median nerve $(\mathrm{MN})$ in the proximal forearm demonstrated in the current study, though lower than $41 \%$ among the Spaniards (Rodriguez-Niedenfuhr et al., (1999), is higher than $2 \%$ among the Japanese (Eid et al., 2011) and $1.6 \%$ among the Indians (Singla et al., 2012). This wide range could be attributed to methodological differences. For example, whereas the present study used total number of MA observed as the denominator in the calculation of incidences of $\mathrm{MN}$ perforated by MA, Rodriguez-Niedenfuhr et al., (1999) used only the total number of palmar type of MA as the denominator. This neurovascular 
relationship is considered to be a phylogenetic remnant as it is commonly observed in some lower primates where it is viewed as an adaptation for extreme muscular movements (Eid et al., 2011). In case of human beings, the MA may compress the nerve fibers immediately surrounding them, resulting in carpal tunnel and pronator teres syndromes (Tsagarakis et al., 2004; Singla et al., 2012; Stavros et al., 2016; Patnaik and Paul, 2016). PMA should therefore be taken into account when assessing entrapment neuropathies involving the median nerve.

\section{Termination}

The PMA terminated in the hand by either uniting with a branch of the ulnar artery to form a median-ulnar type of superficial palmar arterial arch in $8(66.7 \%)$ of cases. This is higher than $4-60 \%$ in contemporary literature (Rodriguez-niedenfuhr et al., 1999; Bilodi et al., 2001; Natsis et al., 2009; Nayak et al., 2010; Raviprassana and Dakshayani, 2014). In such, or where it gives rise to digital branches, its damage may compromise blood supply to the digits (Nejad et al., 2016; Bijannejad et al., 2016). Accordingly, caution should be taken during various surgical procedures on the forearm such as harvesting of vascular flaps and carpal tunnel decompression to avoid iatrogenic injury to the PMA and subsequent inadvertent ischemia of hand muscles.

In conclusion, the median artery is present in nearly $60 \%$ of the population, much higher than in prevailing literature reports. Prevalence of the palmar type of median arteries and that of median arteries piercing median nerves is also higher than in other populations. Accordingly, presence of median artery and consequently other vascular and median nerve variations should be considered in the differential diagnosis of forearm entrapment neuropathies and due caution taken during forearm surgical procedures. We recommend preoperative ultrasound evaluation of the forearm and hand vascular system.

CONFLICT OF INTEREST: There is no conflict of interest in this study

\section{ACKNOWLEDGEMENT}

The authors are grateful to technical staff of the Department of Human Anatomy for technical assistance and Antonina Odock - Opiko for typing the mauscript.

\section{REFERENCES}

1. Acarturk TO, Tuncer U, Aydogan LB, Dalay AC. 2008. Median artery arising from the radial artery: its significance during harvest of a radial forearm free flap. J Plast Reconstr Aesth Surg, 61:5-8.

2. Agarwal KK, Saxena A, Soni S, Das AR. 2013. Persistent median artery: A sign of primitive arterial pattern. OA Case Reports; 13: 128.

3. Agarwal P, Gupta S, Yadav P, Sharma D. 2014. Cadaveric study of anatomical variations of the median nerve and persistent median artery at the wrist. Ind J Plast Surg, 47: 95 - 101.

4. Aragão JA, da Silva ACF, Anunciação CB, Reis FP, 2017. Median artery of the forearm in human fetuses in northeastern Brazil: anatomical study and review of the literature. Anat Sci Int, 92:107-111.

5. Arifoglu Y, Sevinc O, Barnt C, Is M, Diramali M. 2008. Persistent median artery: Case Report and review of the literature. Sinir Sistemi Cerrahisi Derg, 3: 195 - 198.

6. Aung $\mathrm{HH}$, Than TAM. 2009. Incidence of persistent median artery of the forearm in Myanmar adults. Acta Anat Nippon, 84: 202. 
7. Balakrishnan C, Smith MF, Puri P. 1999. Acute carpal tunnel syndrome from thrombosed persistent median artery. The J Emerg Med, 17:437-439.

8. Bijannejad D, Azandeh S, Javadnia F, Gholami MR. Persistent median artery in the carpal tunnel and anastomosis with superficial palmer arch. Case Rep Plast Surg Hand Surg, 2016: 3: 25 27.

9. Bilodi AKS, Nayak SG, Sarwath G. A report on two cases of persistent median arteries. J Inst Med, 2001; 23: $98-104$.

10. Chen L, Chen J, Hu B, Jiang L - X. Sonographic findings of the Bifid Median Nerve and persistent median artery in carpal tunnel: A preliminary study of Chinese individuals. Clinics, 2017; 72: 358 - 362.

11. Eid N, Ito Y, Shibata MA, Otsuki Y. 2011. Persistent median artery: cadaveric study and review of the literature. Clinical Anatomy, 24:627-633.

12. Gassner EM, Schocke M, Peer S, Schwabegger A, Jaschke W, Bodner G. 2002. Persistent median artery in the carpal tunnel: Color Doppler ultrasonographic findings. J Ultrasound Med 21:455-461.

13. George BJ, Henneberg M. 1996. High frequency of the median artery of the forearm in South African newborns and infants. S Afr Med J, 86:175-175.

14. Henneberg, M, George BJ. 1992. High incidence of the median artery of the forearm in a sample of recent southern African cadavers. J Anat, 180:185.

15. Henry BM, Zwinczewska H, Roy J, Vikse J, Ramakrishnan PK, Walocha JA. The prevalence of anatomical variations of the median nerve in the carpal tunnel: A systemic review and meta analysis. PLOS ONE, 2015; 10: e0136477.

http://dx.xoi.org/10.1016/j.jasi.2017.02.003.

16. Kondori BJ, Rahimian E, Tahsini MR, Asadi MH. 2015. Persistent median artery in the carpal tunnel: Anatomy, Embroyology and clinical significance. Sch J Med Case Rep, 3: 646 - 648.

17. Kopuz C, Barris S, Gulman B. 1997. A further morphological study of the persistent median arteries in neonatal cadavers. Surg Radiol Anat, 19: 403 - 406.

18. Lovie MJ, Duncan GM, Glasson DW. 1984. The ulnar artery forearm free flap. British J Plast Surg, 37:486-492.

19. Milligan P. 2013. Persistent median artery and veins in patients undergoing elective day case hand surgery. ESRAS Academy; 33178.

20. Nangole WF, Khainga S, Aswani J, Kahoro L, Vilembwa A. 2015. Free flaps in a resource constrained environment: a five year experience. Outcomes and lessons learned. Plastic Surg Intl. Article ID 194174. http://dx.doi.org/10.1155/2015/194174.

21. Natsis K, Iordache G, Gigis I, Kyriazidou A, Lazaridis N, Noussios G, et al. 2009. Persistent median artery in the carpal tunnel: Anatomy, embryology, clinical significance, and review of the literature. Folia Morphol (Warsz). 68:193-200.

22. Nayak SR, Krishnamurthy A, Kumar SJM, Prabhu LV, Potu BK, D'Costa S, et al. 2010. Palmer type of median artery as a source of superficial palmer arch. A cadaveric study with its clinical significance. Hand, 5: $31-36$.

23. Nejad DB, Azandeh S, Gholami MR, Gharravi AM, Zhaleh M. 2016. Superficial Palmer arch with persistent median artery. J Anat Soc India; 65: 175 - 176.

24. Patnaik M, Paul S. 2016. Persistent median artery of the forearm and palm: a cadaver study into its origin, course, fate and clinical significance. Ital J Anat Embryol, 121:88-95.

25. Potu BK, Ray B, Pai SR, Bhat KMR, Pulakunta T, Sarda R, et al. 2011. A preliminary survey of the median artery in human cadavers in South Indian origin. Bratisl Lek listy, 112: 292 - 295.

26. Raviprasanna KH, Dakshayani KR. 2014. Persistent median artery in the carpal tunnel. Int J Anat Res, 2:589-593. 
27. Rodríguez-Niedenführ M, Sanudo JR, Vázquez T, Nearn L, Logan, B, Parkin I, 1999. Median artery revisited. J Anat, 195:57-63.

28. Salter M, Sinha NR, Szmigielski W. 2011. Thrombosed persistent median artery causing carpal tunnel syndrome associated with bifurcated median nerve: A case report. Pol J Rad, 76:46 - 48.

29. Singla RK, Kaur N, Dhiraj GS. 2012. Prevalence of the persistant median artery. J Clin Diag Res, 6:1454- 1457.

30. Srivastava SK, Pande BS. 1990. Anomalous pattern of median artery in the forearm of Indians. Acta Anat, 138: 193 - 194.

31. Stavros K, Park D, Motiwala R, Weinberger J, Zhou L, Shin S. 2016. Median nerve penetration by a persistent median artery and vein mimicking carpal tunnel syndrome. Muscle and Nerve, 53: $485-487$.

32. Stimpson JA, Gupta A. 2012. Persistent median artery (palmer type) and median nerve block in the forearm: Observational study of prevalence. Reg Anesth Pain Med, 37: $558-560$.

33. Tsagarakis M, Tarabe M, Minoyiannis N, Tserotas $P$, Komninakis E. 2004. Management of traumatic complete laceration of the median artery at the carpal tunnel: repair or ligate? Plast Reconst Surg, 114:1014-1015.

34. Tsuruo Y, Ueyama T, Ito T, Nanjo S, Gyoubu H, Satoh K et al. 2006. Persistent median artery in the hand: a report with a brief review of the literature. Anat Sci Int; 81: $242-252$.

35. Varley I, Wales CJ, Carter LM. 2008. The median artery: its potential implications for the radial forearm flap. J Plast Reconst Aesth Surg, 61:693-695.

36. Walker FO, Cartwright MS, Blocker JN, Arcury TA, Suk JI, Chen H, et al 2013. Prevalence of bifid median nerves and persistent median arteries and their association with carpal tunnel syndrome in a sample of Latino poultry processors and other manual workers. Muscle \& nerve, 48:539-544. 